\title{
CARACTERIZAÇÃO DA PRÁTICA ESPORTIVA/RECREATIVA DO SKATE EM SÃO PAULO, PARANÁ E RIO GRANDE DO SUL
}

Recebido em: 17/06/2015

Aceito em: 26/10/2015

\author{
Luana Mari Noda ${ }^{1}$ \\ Giuliano Gomes de Assis Pimentel ${ }^{2}$ \\ Universidade Estadual do Maringá - UEM \\ Maringá - PR - Brasil
}

RESUMO: Caracterizamos a prática do skate a partir do entendimento de seus praticantes. A amostra foi constituída por 184 skatistas entre 16 e 60 anos de idade, em pistas de Maringá-PR, Porto Alegre- RS e São Bernardo do Campo- SP, em pesquisa tipo survey. Dentre os aspectos que caracterizam o skate, $70 \%$ da amostra tomam o skate como opção de lazer, uma vez que a diversão (79\%) é o motivo à prática mais citado. Embora só $16 \%$ consentiram que fazem parte de alguma "tribo" de praticantes, $33 \%$ afirmaram já ter sofrido algum tipo de preconceito. À análise percebemos que não há muitos consensos sedimentados entre os skatistas, mesmo dentro de cada modalidade. A caracterização dos sujeitos e da prática varia a partir de traços ora regionais ora geracionais. Em conclusão, os resultados permitem questionar afirmações mitificadas sobre essa atividade de aventura.

PALAVRAS CHAVE: Atividades de lazer. Esportes. Patinação.

\section{CHARACTERIZATION OF SPORTS/RECREATIONAL PRACTICE OF SKATE IN SÃO PAULO, PARANÁ AND RIO GRANDE DO SUL}

ABSTRACT: This paper deals with the perception of skateboarders on their own characteristics and the form how they experience and represent the skateboard. The sample consisted of 184 skateboarders of 16 to 60 years old, from skate parks of Maringa-PR, Porto Alegre-RS and São Bernardo do Campo-SP in survey research. Among the aspects that characterize the skateboard, $70 \%$ of the sample take skateboarding as a leisure option, since the divertissement $(79 \%)$ is the most cited reason to practice. Although only $16 \%$ agreed that were part of "tribe" of practitioners, $33 \%$ said they had suffered some kind of preconception. In the analysis we realized that there are not many sedimented consensuses among the skateboarders, even within each modality, standing that the culture surrounding this practice varies from traits regional sometimes generational. From the results can question mystified statements about this adventure activity.

\footnotetext{
${ }^{1}$ Graduada em Educação Física pela Universidade Estadual de Maringá. Membro do Grupo de Estudos do Lazer (GEL).

${ }^{2}$ Docente do Departamento de Educação Física e do Programa de Pós Graduação em Educação Física da Universidade Estadual de Maringá. Líder do Grupo de Estudos do Lazer (GEL).
} 
KEYWORDS: Leisure activities. Sports. Skating.

\section{Introdução}

No campo dos Estudos do lazer, a literatura sobre aventura teve forte impulso nos anos 1990, nas quais os primeiros trabalhos possuíam uma perspectiva mais panorâmica e ensaística sobre o fenômeno. Desde então a produção baseada em estudos campo (REINHART, 2010; PETRONE, 2010; BASTOS, 2006; UVINHA, 2001) pondera que o significado dado às práticas de aventura é singular em cada modalidade e até varia dentro da mesma modalidade conforme cada local. Este estudo foi motivado pela suspeita de que ainda predominam especulações em torno do fenômeno esportivo e recreativo da aventura frente a poucos estudos empíricos.

Frente a essa premissa, nos debruçamos sobre a prática do skate em três cidades brasileiras a fim de verificar, pelo mesmo instrumento, o que caracteriza em comum e o que dá especificidade local a uma mesma atividade de aventura. Selecionamos o skate por ser a atividade esportiva de aventura mais representativa no território urbano brasileiro (BITENCOURT e AMORIM, 2005).

O skate é uma prática social que vem se fazendo presente no cotidiano urbano, seja como meio de transporte, opção de lazer, atividade física ou esporte competitivo. Dentre as práticas de aventura, é uma das mais praticadas e conhecidas. De certo modo, o skate é uma prática de lazer que está presente no tempo livre de parte da juventude, indo além do esporte, pois está relacionado também a estilos de vida (UVINHA, 2001; PIMENTEL e SAITO, 2010; PAIXÃO, 2014).

Por isso, a problemática deste estudo é: Como os praticantes de skate se representam e quais dessas características variam regionalmente? Ademais, o skate configura-se como fenômeno sociocultural a ser estudado e compreendido, 
especialmente quando as políticas públicas em torno do skate carecem de informações sobre os sujeitos da prática (SILVA, 2005).

Dada essa lacuna no conhecimento, o presente estudo elucida características acerca da modalidade, tendo como ponto de partida características gerais (sexo, idade, renda, lesões) e as representações sociais dos skatistas. Por representações sociais entendemos o conhecimento compartilhado por um determinado grupo social de forma 'naturalizada' (MAFFESOLI, 2001).

Assim, identificamos como o próprio skatista concebe sua prática à medida que conhecemos os consensos e dissensos dessa comunidade sobre o skate. Em suma, a pesquisa teve como objetivo analisar a percepção de skatistas sobre as suas próprias características e a forma como vivenciam e representam o skate.

\section{Aspectos Metodológicos}

A pesquisa é descritiva, tipo survey. A amostra foi composta por 184 skatistas distribuídos entre Paraná, São Paulo e Rio Grande do Sul, sendo 177 do gênero masculino, com idades entre 16 e 60 anos. Estes foram selecionados de forma nãoprobabilística, pois não houve organização estatística para distribuição da amostra nas diferentes localidades de coleta.

Ainda quanto à caracterização de amostra, 52\% possuem pelo menos a formação de Ensino Médio completo ou superior incompleto. Entre praticantes das três cidades, Maringá, Porto Alegre e São Bernardo do Campo, a renda familiar líquida mais citada é de até quatro salários mínimos. Segundo a Pesquisa DataFolha, requisitada pela Confederação Brasileira de Skate e realizada em 2006, há predominância dos extratos de consumo tipos "B" e "C" entre os praticantes de skate. 
O maior número de praticantes $(47,37 \%)$ da amostra se considera skatista amador, de nível recreativo e competitivo em Maringá. Já em Porto Alegre (71\%) e São Bernardo (44\%), a categoria mais citada foi de amador, nível recreativo. Segundo o IBGE, 2007, sobre as Regiões de Influência das Cidades, Maringá é considerada um centro regional, São Bernardo do Campo, região metropolitana de uma metrópole global e Porto Alegre, metrópole nacional. Assim, a pouca diversidade de opções em cidades menores com menor população permite aos skatistas se envolverem nas competições locais enquanto em São Bernardo e Porto Alegre a grande massa de praticantes e a maior seletividade/representatividade das competições refletem uma base piramidal formada por amadores, nível recreativo.

Em São Bernardo do Campo a faixa etária mais representativa dentre os entrevistados foi de 21 a 30 anos (51\%) seguido de 31 a 40 anos (24\%) enquanto em Maringá e Porto Alegre a faixa mais significativa foi entre 16 e 20 anos, com 46\% e $54 \%$ respectivamente. Somando todas as cidades pesquisadas $52 \%$ afirmam praticar a modalidade semanalmente o que pode estar relacionado à facilidade de transporte e local para a prática.

Quanto ao local de coleta, selecionamos os "picos", como são designados os lugares de referência. Assim para o presente estudo foi necessário selecionar os lugares relevantes na cultura dos skatistas nos estados de São Paulo, Paraná e Rio Grande do Sul. Escolhemos pistas centrais que recebem praticantes além dos que residem nas proximidades, uma vez que as pesquisas de Bastos (2006) revelou a tendência dos praticantes a procurar conhecer os pontos mais centrais do skate na cidade à medida que querem aprimorar suas manobras.

Em São Bernardo do Campo - SP, a pista no Parque da Juventude é segundo Sandro Dias, hexacampeão da Word Cup Skateboarding, a melhor pista pública no 
Brasil em entrevista ao site 360 graus. Em Porto Alegre - RS a pista snake no Parque da Marinha é a maior pista da modalidade no País de acordo com o site SKoito. Em pesquisa realizada em Maringá - PR, Balbim, Nogueira Filho e Garcia (2010) observaram que os equipamentos específicos da prática do skate modalidade street por vezes não são utilizados tanto quanto os locais considerados impróprios para a prática, mas que são identificados como locus pelos praticantes.

Para coleta de dados junto aos sujeitos, o instrumento (estruturado e validado) utilizado foi "Questionário GEL - Definição e Caracterização das Atividades de Aventura” (BALBIM; OLIVEIRA e PIMENTEL, 2009). O questionário é apropriado ao skate, sendo composto por trinta e duas questões divididas em dois blocos. O primeiro bloco possui 9 questões objetivas, da primeira a sétima questões de respostas únicas a oitava e nona questões são de múltipla escolha. Que buscam estabelecer informações a respeito do sujeito. O segundo bloco é composto de 23 questões objetivas em que as respostas são divididas em 5 graus de concordância: 1- Discordo plenamente, 2- Discordo em parte, 3- Não concordo nem discordo ou Não tenho opinião, 4Concordo parcialmente e 5 - Concordo plenamente.

A matriz analítica foi construída a partir de outros estudos e literatura vigente, sendo posteriormente apresentada a especialistas para juízo crítico. $\mathrm{O}$ instrumento foi validado e objetivado em coletas-piloto nas cidades de Paranavaí e Maringá, ambas no Paraná (BALBIM; OLIVEIRA e PIMENTEL, 2009).

Entre os limites do trabalho destacamos: a) não foi realizada correlação estatística quanto à proporcionalidade populacional das cidades para o ' $n$ ' de instrumentos; b)houve seleção por conveniência e não se realizou a estratificação ou randomização da amostra, c) as coletas se efetivaram em estações diferentes: Outono em Porto Alegre e Inverno em Maringá e São Bernardo; d) a distribuição de praticantes 
por modalidade/cidade não possui representatividade, mas é, sobretudo, resultado dos locais onde os dados foram coletados, no sistema de amostra por conveniência.

Os participantes consentiram em responder ao questionário e os resultados foram tabulados e remetidos aos sujeitos que, optativamente, escreveram o endereço eletrônico para receberem retorno sobre o estudo. O projeto foi aprovado no Comitê de Ética local.

\section{Afinal, O que Caracteriza o Skate?}

Os resultados (expressos em frequência e percentual) estão apresentados nas tabelas abaixo. A primeira diz respeito à concordância com afirmações sobre skate numa escala de Licket. O primeiro conjunto de afirmações trazia as classificações mais comuns para as atividades de aventura.

Tabela 01: Grau de concordância em relação à terminologia

\begin{tabular}{|l|l|l|l|l|}
\hline & Maringá & Porto Alegre & São Bernardo & Total \\
\hline Lazer & $62 / 67 \%$ & $40 / 78 \%$ & $31 / 79 \%$ & $133 / 72 \%$ \\
\hline Esporte Radical & $76 / 83 \%$ & $45 / 87 \%$ & $34 / 87 \%$ & $155 / 84 \%$ \\
\hline Esporte de Aventura & $56 / 60 \%$ & $30 / 58 \%$ & $22 / 56 \%$ & $108 / 59 \%$ \\
\hline Esporte de Risco & $58 / 63 \%$ & $28 / 54 \%$ & $26 / 67 \%$ & $112 / 61 \%$ \\
\hline AFAN & $14 / 15 \%$ & $14 / 29 \%$ & $6 / 15 \%$ & $34 / 18 \%$ \\
\hline
\end{tabular}

É predominante o entendimento do skate como um esporte radical. Os autores que partem dessa terminologia são Uvinha (2001) e Pereira; Armbrust; Ricardo (2008). Para Pereira, Armsbrust e Ricardo (2008), os esportes radicais podem ser divididos em dois tipos distintos: ação e aventura. Para este autor o skate é um esporte radical de ação, caracterizado pelas manobras que exigem força e velocidade, por ser praticado em espaços urbanos construídos e o publico alvo que se relacionam por meio de atitudes, vestimentas, comportamentos e linguagens. 
Entretanto, ao caracterizar o skate como esporte radical pode-se entender que esta nomenclatura seria de uso entre outras atividades de aventura. Mas segundo Dias (2007) há recusa na adoção do conceito de esporte radical por parte de alguns esportistas, que julgam tal empreendimento como "uma denominação sensacionalista, criada pela mídia". De fato, considerando a realidade dos Extreme Games e sua tradução no Brasil para esportes radicais, o termo é o mais antigo para agrupar skate e modalidades dos X-games, sendo reforçado pelos resultados a legitimidade entre os skatistas pesquisados.

Não obstante o termo esporte radical ser assimilado pelos skatistas há entraves à sua disseminação na atualidade. Primeiro, no turismo de aventura esse termo é evitado devido à percepção negativa que gera nas pessoas não-iniciadas ao meio (PIMENTEL e SAITO; 2010). Também no campo acadêmico o termo é pouco recorrente, sendo basicamente utilizado na produção de dois autores: Ricardo Uvinha e Dimitri Pereira. Ademais tanto a adjetivação radical quanto a definição de esporte não contemplam o universo ainda em expansão das atividades de aventura (PIMENTEL, 2013).

Dentre os aspectos que caracterizam o skate, o grau de concordância se manteve em relevante em dois aspectos: o skate como forma de aliviar o stress do cotidiano $72 \%$ e a aventura com $54 \%$.

Tabela 02 - Nível de concordância na relação skate e lazer

\begin{tabular}{|l|l|l|l|l|}
\hline & Maringá & $\begin{array}{l}\text { Porto } \\
\text { Alegre }\end{array}$ & $\begin{array}{l}\text { São } \\
\text { Bernardo }\end{array}$ & Total \\
\hline $\begin{array}{l}\text { Sua prática pode ser } \\
\text { considerada uma opção de } \\
\text { lazer }\end{array}$ & $62 / 67 \%$ & $40 / 78 \%$ & $31 / 79 \%$ & $133 / 72 \%$ \\
\hline $\begin{array}{l}\text { Sua prática tem como maior } \\
\text { objetivo a competição }\end{array}$ & $10 / 11 \%$ & $4 / 8 \%$ & $6 / 15 \%$ & $20 / 11 \%$ \\
\hline $\begin{array}{l}\text { Sua prática é uma forma de } \\
\text { aliviar o estresse do } \\
\text { cotidiano }\end{array}$ & $64 / 69 \%$ & $40 / 77 \%$ & $29 / 74 \%$ & $133 / 72 \%$ \\
\hline $\begin{array}{l}\text { Você é atraído pelo lazer de } \\
\text { risco }\end{array}$ & $45 / 50 \%$ & $20 / 39 \%$ & $22 / 56 \%$ & $87 / 47 \%$ \\
\hline
\end{tabular}


Podemos notar que cerca de $70 \%$ da amostra concorda com a afirmação de o skate ser uma opção de lazer e uma forma de aliviar o estresse do cotidiano, o que geralmente ocorre nos momentos de lazer. Seguindo este pensamento os praticantes não consideram a competição como o maior objetivo da prática de skate. Corroborando com isso, Marinho (2008) salienta que as atividades de aventura estão sendo entendidas como diversas práticas manifestadas, privilegiadamente nos momentos de lazer. Isso não significa que a competição descaracterize o lazer. Pelo contrário, é um de seus elementos, especialmente no lazer esportivo. O que chama atenção no skate é que a configuração da vivência dele como lazer esportivo se baseia mais na liberação das tensões e na busca do desafio do que na superação do outro por meio de regras.

O contato da natureza na cultura do skate não é uma característica evidenciada pelos skatistas, em Maringá apenas 24\% dos entrevistados concordam com a afirmação “O contato com a natureza é algo que caracteriza o skate”. Em Porto Alegre e São Bernardo há pouca alteração, $33 \%$ e $26 \%$ respectivamente. Talvez por isso a afirmação de que o skate gera algum impacto a natureza seja veemente rejeitada pelos entrevistados, apenas sete skatistas concordaram com a afirmação entre todas as cidades. Assim como a relação de causas sociais ou de preservação da natureza a modalidade, em média apenas $15 \%$ concordaram com esta relação.

Percebe-se que não existe um consenso entre os praticantes quanto a relação do skate com a natureza, exceto quando é colocado a geração de impactos na natureza decorrentes da prática de skate. Mas vemos o skate como uma modalidade que mesmo sendo urbana depende de alguns fenômenos naturais como o vento, empuxo e gravidade, elementos esses que segundo Dias; Melo e Alves Junior (2007) servem como propulsores dos deslocamentos e deslizes envolvidos nas ações esportivas.

Por fim, o que motiva esses sujeitos à prática? 
Tabela 3: Motivação à prática

\begin{tabular}{|l|l|l|l|l|}
\hline & Maringá & $\begin{array}{l}\text { Porto } \\
\text { Alegre }\end{array}$ & $\begin{array}{l}\text { São } \\
\text { Bernardo }\end{array}$ & Total \\
\hline Diversão & $73 / 79 \%$ & $42 / 87 \%$ & $29 / 74 \%$ & $144 / 78 \%$ \\
\hline Gosto pelo risco* & $63 / 34 \%$ & $46 / 48 \%$ & $27 / 34 \%$ & $136 / 24 \%$ \\
\hline Sociabilidade & $41 / 44 \%$ & $25 / 52 \%$ & $16 / 41 \%$ & $82 / 45 \%$ \\
\hline $\begin{array}{l}\text { Desenvolvimento } \\
\text { pessoal* }\end{array}$ & $74 / 26 \%$ & $70 / 49 \%$ & $33 / 28 \%$ & $177 / 32 \%$ \\
\hline
\end{tabular}

* referente a três alternativas que remetem a motivação à prática.

Comparando os dados do estudo com material obtido por Paixão (2014) em uma cidade do interior mineiro, podemos verificar que os praticantes citam os mesmos motivos, apenas acrescentam um novo fator "a prática de uma modalidade não convencional". As questões que rementem a adrenalina e ao risco foram os mais lembrados pelos praticantes de Minas Gerais.

Em pesquisa realizada por Pereira (2006) em São Bernardo do Campo, 82\% dos entrevistados afirmam que a principal influência para o início da prática são os amigos. Porém, quando a questão da motivação para a prática cotidiana é levantada, os respondentes colocam a diversão como aspecto principal da prática, corroborando observações etnográficas de Uvinha (2001).

De fato, a dimensão lúdica é presente como um marcador de como o praticante em geral prefere relacionar-se com o skate. Essa forma descompromissada (isto é, sem uma manifestação política clara), não elimina uma manifestação de resistência ao poder. Reinhart (2010), por exemplo, ao encontrar skatistas na Berlim Oriental, nota que os mesmos resistem muito mais ao preconceito contra sua prática do que ao Comunismo, que os mantinha sob vigilância. Logo, elementos mais hedonísticos são os aspectos predominantes na representação do motivo à prática, o que parece se estender à própria sociabilidade fruída entre os skatistas: fluida e provisória, no sentido dado por Maffesoli (2001) às tribos urbanas, mesmo que skatistas em geral não se percebam desta forma (até porque estes não fixam suas identidades, conforme veremos no próximo tópico). 


\section{Como o Skatista se Vê?}

Comumente a palavra "tribo" é usada no âmbito acadêmico para atribuir aos grupos praticantes do skate, entretanto contrariando a essa perspectiva apenas $16 \%$ dos entrevistados concordaram com a afirmação "Você faz parte de alguma 'tribo' de praticantes".

A partir da noção de lugar como um espaço que se transformou à medida que adquiriu identidade e significado (TUAN, 1983), na aproximação com a atividade, se pode observar que as pistas de skate e locais propícios à prática são um locus marcado por conhecimento e experiências coletivas. Magnani (1992, p. 95) identifica a existência de lugares em que os frequentadores se reconhecem enquanto portadores dos mesmos símbolos que remetem a gostos, orientações, valores, hábitos de consumo e modo de vida semelhante.

Para eles, o skate é ainda uma prática vista com reservas? Em Maringá 50\% dos entrevistados afirmou já ter sofrido algum tipo de preconceito por praticar skate. Em Porto Alegre 31\%, e em São Bernardo do Campo 20\% dos skatistas. Coincidentemente, a percepção de preconceito -que é algo nem sempre tangível- é proporcionalmente menor conforme o tamanho da cidade e a tradição do skate nela.

Esses resultados são mais brandos quando comparados aos estudos de Galliano e Mayer (2009) em que $88 \%$ dos entrevistados paranaenses e $70 \%$ da mostra gaúcha afirmaram que o skate é um esporte que sofre preconceito. Por outro lado, nosso instrumento focou o preconceito sofrido pelo entrevistado, o que é diferente da percepção dele sobre se o entrevistado considera se outros já sofreram preconceito.

Segundo Pereira e Armbrust (2010, p. 91), “[...] o skate passou por diversos períodos de recriminação e contestações que, muitas vezes, ficou arraigada na sociedade 
uma visualização dessa prática associada à marginalidade e pessoas desocupadas”. Logo, talvez estejamos diante do refinamento dessa discriminação, de modo que ele não se torna tão explícita e nem mais a todos os skatistas.

Em pesquisa survey junto à população da região metropolitana de Maringá, as pessoas comuns do cotidiano em geral demonstram conhecimento do skate como uma atividade de aventura, mas não há o mesmo interesse em praticá-lo. Ainda, em relação ao skate se verificou a época que a polícia não possuía perfis criminais que discriminem essa prática concomitante há o crescimento de lojas especializadas para venda de produtos ligados ao estilo de vida skatista (PIMENTEL e SAITO, 2010).

Enfim, até por instigar a ocupação do espaço urbano para práticas lúdicas nãousuais, o skate, em seu início, gerou desconfiança, especialmente porque vem associado à irreverência, contestação e subversão (REINHART, 2010; BASTOS, 2006). Em nossa análise, o lazer teve um momento predominantemente desviante. Como toda nova prática, conforme cada contexto regional e momento histórico, dois estratagemas concorreram para seu 'tratamento': a sedução, seguida da incorporação a algum sistema estatal ou paraestatal, com regulamentação das práticas; ou a disciplina, coma exclusão sob a forma de recriminação ou até sua criminalização.

No caso do skate, nos parece que de forma articulada, o biopoder (estatal e de mercado) cuidou para domesticar o skate por meio de sua esportivização, o que foi endossado por grande parte dos praticantes, tendo em vista o imaginário das grandes competições, da profissionalização e das coberturas jornalísticas. A isso, a partir de categorias foucaultianas (FOUCAULT, 2000), poderíamos chamar de dispositivo de controle. Eles nem sempre nos oprimem diretamente, mas estrategicamente respondem a emergências e gradativamente vão se tornando sutis a ponto de as assimilarmos quando não resistimos a elas. 
Esse aspecto foi bem captado por Uvinha (2001) entre skatistas do grande ABC paulista. Ao mesmo tempo em que o mass media, ao cobrirem o novo 'esporte radical', conclamava os praticantes ao consumo de novos produtos, o próprio skate se tornara um produto imaginário, dócil à venda de uma "imagem jovem" no sentido subjetivado de juventude em potência. Por outro lado, resistências e não adesões seja ela críticas ou ingênuas são observadas, especialmente na forma como os praticantes mantém a prerrogativa do skate como estilo de vida, no qual esporte, brincadeira, transporte, sociabilidade e arte são possíveis, tanto em versões mais pasteurizadas quanto, especialmente, naquelas tidas como underground e/ou não-usuais.

Para ilustrar a relação por vezes de rebeldia e noutras de institucionalização no skate, um aspecto notabilizado no estudo é a aceitação por mais da metade dos entrevistados sobre a possibilidade de se ensinar o skate na escola. Em São Bernardo do Campo, se chegou a $74 \%$ de concordância com essa possibilidade. Parte dos skatistas, todavia, ainda considera que o skate não pode ser ensinado. Petrone (2010), ao estudar a comunidade de skatistas considera que essa postura advém de uma postura seletivista, na qual seu aprendizado depende do mérito do aprendiz e de seu desenvolvimento dentro da tribo. Na história do skate, especialmente na modalidade vertical, houve influência da sub-cultura punk, na qual o lema do skate era "skate e destruição" (REINHART, 2010). Nesse caso, o skate, como prática juvenil, era uma forma de desobediência ao sistema e ironia frente ao mundo adulto. Por isso, qualquer estratégia de controle do skate, como sua escolarização, era refutada.

Por outro lado, como pondera Uvinha (2001), para dar mais visibilidade à prática, parte dos próprios skatistasbusca interações com instituições, a partir das quais possam obter alianças ou vantagens para a prática do skate. Por isso, em nossa análise, já começa a se tornar mais recorrente a pedagogização do skate tanto em sua inclusão 
assistemática em projetos ou atividades recreativas ou de forma mais sistematizada no sistema escolar, a exemplo de Pereira e Ambrust (2010).

Para finalizar, precisamos indagar em que medida ocorre preconceito de gênero dentro do universo skatista. Quando questionados, por exemplo, sobre a capacidade feminina, apenas $11 \%$ dos entrevistados afirmam que a mulher é mais frágil no skate. Todavia, mesmo as meninas não sendo percebidas como incapazes, a participação delas é desproporcionalmente inferior. Não por menos, apenas 07 dos 184 entrevistados na pesquisa serem mulheres, uma vez que o survey foi aleatório na amostragem.

Portanto, mesmo que a maioria dos homens skatistas não relate a mulher como inábil, não se pode analisar a disparidade como exclusivamente resultante do desinteresse feminino ou do preconceito externo. Estudos como de Machado (2013) no Brasil e de Porter (2003) no Canadá situam como há reservas às mulheres na prática do skate.

É importante frisar que nossos dados não são evidentes sobre desigualdade de gênero no skate, mas é forçoso reconhecer um duplo movimento entre o empírico e a literatura acadêmica: 1) os dados nem sempre são transparentes e menos ainda possuem correspondência direta com o que a literatura da área postula; 2) nosso survey foi um instrumento fértil para fornecer dados, mas entendemos que, sobretudo, nos fornece novas questões a serem respondidas em estudos de profundidade.

\section{Conclusões}

Alguns apontamentos gerais são possíveis, uma vez que skatistas possuem uma relação hedonística com sua prática, o que favorece entenderem-na como lazer. Tanto se vêem sujeitados a preconceitos quanto buscam se desvencilhar da identificação com alguma tribo. A participação das mulheres no skate não é objeto de resistência explícita, 
mas é claro que elas estão invisibilizadas nesse meio. Como há uma receptividade ao ingresso do skate na escola, desdobramentos voltados ao ensino de skate para todos os gêneros se justificam nas políticas esportivas educacionais de lazer.

Frente à quantidade de dados gerados, é claro que o survey reforça a dimensão peculiar do skate em cada uma das cidades estudadas. Três inferências concorrem e se complementam para pensar essa disparidade nos resultados. Primeiro, a óbvia carência de uma pesquisa de âmbito nacional ou de uma revisão sistemática da produção nacional a fim de apontar a influência dos fatores regionais nas dimensões analisadas para caracterizar a prática e o praticante de skate no Brasil.

Segundo, o próprio limite metodológico dos estudos, ainda tateando sobre um objeto cujo tamanho e repercussão oscila entre estimativas infladas e subdimensionadas de sua representatividade. Para exemplificar, no Atlas do Esporte do Brasil, Bitencourt e Amorim (2005), não obstante a realização de uma pesquisa panorâmica não explica como Porto Alegre é a capital com maior número de skatistas estando Rio de Janeiro em quinta posição, quando, no mapeamento dos "picos" ou "points" são mencionados duas referencias gaúchas contra cinco fluminenses. (BITENCOURT e AMORIM, 2005, p. 421).

Por fim, um terceiro aspecto, é forçoso reconhecer - diante dos fatos - que o skate não só é uma prática com variação regional, mas, especialmente, de mutabilidade acelerada, conforme se evidencia nas suas fases cíclicas de declínio e florescimento e, também, na diversificação de modalidades frente à conjugação das características dos praticantes e do desenvolvimento tecnológico de novos modelos (para variados terrenos e performances) e espaços de prática.

Questões como formação de "tribos" e pedagogização ainda necessitam de maiores estudos. Acreditamos que os dados e as discussões impulsionam 
questionamentos de diferentes dimensões. A influência dos fatores regionais na caracterização da prática e as limitações que a partir deste estudo possam ser superadas para maior compreensão do skate no Brasil.

\section{REFERÊNCIAS}

BALBIM, G. M; FILHO, K.N; JUNIOR, E. G. Percepção dos skatistas do estilo "street" da cidade de Maringá-PR em relação a estrutura dos locais de prática. In: CONGRESSO BRASILEIRO DE ATIVIDADE DE AVENTURA, 5, 2010, São Bernardo do Campo. Anais... CBAA, 2010, p. 140-165.

BALBIM, G. M.; OLIVEIRA, R. M. S. B.; PIMENTEL, G. G. A. Instrumento GEL/2009 de pesquisa sobre atividades de aventura. In: ENCONTRO DE LAZER DO PARANÁ, 4, 2009, Marechal Cândido Rondon: Unioeste. Anais... ELAP. 2009. v. 1. p. $1-6$.

BASTOS, B. C. Estilo de vida e trajetórias sociais de skatistas; da "vizinhança" ao "corre". 2006. 174f. Tese (Mestrado)-Escola de Educação Física. Universidade Federal do Rio Grande do Sul. Porto Alegre, 2006.

BITENCOURT, V.; AMORIM, S. Skate. In: DACOSTA, L. P. (Org.). Atlas do esporte no Brasil. Rio de Janeiro: Shape, 2005.

DATAFOLHA. Praticantes de skate: penetração nos lares 2009. Instituto de Pesquisa Datafolha, Opinião Pública, dossiês. Disponível em http://www.cbsk.com.br . Acesso em: 10 mar. 2015.

DIAS, C. A. G. Notas e definições sobre esporte, lazer e natureza. Licere, Belo Horizonte, v. 10, n. 3, p. 1-36, 2007.

DIAS, C. A. G.; MELO, V.; ALVES JÚNIOR, E. D. Os estudos dos esportes na natureza: desafios teóricos e conceituais. Revista Portuguesa de Ciências do Desporto. Porto, v. 7, p. 65-95, 2007.

FOUCAULT, M. Microfísica do poder. Rio de Janeiro: Graal, 2000.

GALLIANO, L. M; MAYER, S. Motivos que levam os skatistas à prática do esporte: um estudo comparativo entre os estados do Paraná e Rio Grande do Sul. In: FIEP Bulletin, 2009. Anais... Congresso Internacional de Educação Física.

IBGE. Regiões de Influência das Cidades 2007. Disponível em: http://www.ibge.gov.br Acesso em: 10 mar. 2015.

MACHADO, G. M. C. As mulheres e o "carrinho": gênero e corporalidade entre os skatistas. In: SEMINÁRIO INTERNACIONAL FAZENDO GÊNERO 10, 2013, Florianópolis. Anais...Florianópolis, 2013. 
MAFFESOLI, M. Sobre o nomadismo: vagabundagens pós-modernas. Rio de Janeiro: Record, 2001.

MAGNANI, J. G. C. Tribos urbanas. Cadernos de Campo, v.2, n. 2, São Paulo, 1992.

MARINHO, A. Lazer, aventura e risco: reflexões sobre atividades realizadas na natureza. Movimento. Porto Alegre, v. 14, n. 2, p. 181-206, 2008.

PAIXÃO, J. A. Práticas aventureiras de skatistas em espaços urbanos ressignificados. Licere, Belo Horizonte. v. 17, n. 2, p. 147-164, jun. 2014.

PEREIRA, D. W. Perfil de skatista do parque da juventude em São Paulo. IN: CONGRESSO BRASILEIRO DE ATIVIDADES DE AVENTURA,1, 2006, Balneário Camboriú/SC. Anais... CBAA, 2006.

; AMBRUST, I. Pedagogia da aventura: os esportes radicais, de aventura e de ação na escola. Jundiaí: Fontoura, 2010

; ARMBRUST, I; RICARDO, D. P. Esportes radicais de aventura e ação, conceitos, classificações e características. Corpoconsciência, Santo André, v. 12, n. 1, p. 37-55, 2008.

PETRONE, K. "You have to hit a couple times". The role of conflict in learning how to "be" a skateboard. Teaching and TeacherEducation, Nebraska, v. 26, p. 119-127, 2010 .

PIMENTEL, G. G. A. Esportes na natureza e atividades de aventura: uma terminologia aporética. Rev. Bras. Ciênc. Esporte, Porto Alegre, v. 35, n. 3, 2013

PIMENTEL, G. G. A.; SAITO, C. F. Caracterização da demanda potencial por atividade de aventura. Motriz, Rio Claro, v. 16, p. 152-161, 2010.

PORTER, N. L. Female skateboarders and their negotiation of space and identity.Master thesis in Communication Studies, Concordia University, 2003.

REINHART, K. "I ollied the Berlin wall". Skateboarding in socialist east Germany, Stadion, Sankt Augustin, v.36, p. 157-176, 2010.

SILVA, J. A. A. Política de esporte e lazer como educação emancipatória da juventude: contradições e possibilidades das políticas democráticas e populares. Tese (Doutorado em Educação) Universidade Federal da Bahia, 2005.

TUAN , Y. F. Espaço e lugar a perspectiva da experiência. São Paulo: Difel, 1983.

UVINHA, R. R. Juventude, lazer e esportes radicais. São Paulo: Manole, 2001.

Agradecimentos: aos integrantes do Grupo de Estudos do Lazer (GEL/UEM/CNPq) pela participação na coleta dos dados. 
Giuliano G. de Assis Pimentel

\section{Endereços dos Autores:}

Luana Mari Noda

Rua Kakogawa, nº 497 - Parque das Grevíleas

Maringá - Paraná - 87.025-000

Endereço Eletrônico: luasns@hotmail.com

Giuliano Gomes de Assis Pimentel

Departamento de Educação Física

Universidade Estadual de Maringá

Av. Colombo 5790 - Campus Universitário

Maringa - PR - 87.020-900

Endereço Eletrônico: ggapimentel@uem.br 